\title{
Heart rate variability and soccer training: a case study
}

\author{
Maurício Gattás Bara-Filho ${ }^{1}$ \\ Daniel Schimitz Freitas ${ }^{1}$ \\ Débora Moreira $^{1}$ \\ Marcelo de Oliveira Matta ${ }^{1}$ \\ Jorge Roberto Perrout de Lima ${ }^{1}$ \\ Fábio Yuzo Nakamura ${ }^{2}$ \\ ${ }^{1}$ Faculdade de Educação Física e Desportos, Universidade Federal de Juiz de Fora, Juiz de \\ Fora, MG, Brazil \\ ${ }^{2}$ Centro de Educação Física e Esporte, Universidade Estadual de Londrina, Londrina, PR, Brazil
}

\begin{abstract}
O objetivo do presente estudo foi monitorar as mudanças nos índices da VFC em dois jogadores da mesma equipe de futebol durante um período de treinamento. A carga de treinamento de cada sessão foi monitorada durante 3 semanas pelo método TRIMP. Os intervalos RR de repouso na posição supina foram obtidos em cinco diferentes momentos durante três semanas. Os índices da VFC (SD1, SDNN, RMSSD e HF) apresentaram padrões semelhantes em M1, mas em M2, estes valores foram maiores no atleta 1 quando comparados ao atleta 2. Em M2 e M4, o atleta 1 apresentou um rebote parassimpático em SD1, SDNN e RMSSD, enquanto o atleta 2 apresentou redução deste índices. Pode-se concluir que os índices da VFC podem ser úteis para monitorar os efeitos do treinamento de futebol na modulação parassimpática, sendo sensíveis a períodos de estresse e recuperação.
\end{abstract}

Keywords: Frequência cardíaca. Variabilidade. Futebol.

\section{Variabilidade da frequência cardíaca e treinamento de futebol: um estudo de caso}

Resumo: The aim of this study was to monitor changes in HRV indices of two players of the same soccer team during a training period. Training loads of each session of the 3-week period were monitored by means of the training impulses (TRIMP) method. Resting RR intervals at supine position were obtained at five moments over 3-week period. The HRV indices (SD1, SDNN, RMSSD and HF) followed similar inter-subject patterns. They had similar values at M1 and, from M2, these variables were greater in athlete 1 than in athlete 2. At M2 and M4, athlete 1 presented a parasympathetic rebound, especially in SD1, SDNN and RMSSD, whereas athlete 2 presented reduction of these indices. We can advance that indices of HRV can be useful to monitor the effects of soccer training/competitive loads on parasympathetic modulation, being sensitive to both individual characteristics and to periods of stress and recovery.

Palavras-chave: Soccer. Heart rate. Variability.

\section{Introduction}

Soccer players perform high-intensity intermittent activities of short duration, interspersed with low intensity recovery periods, over 90 min during competitive matches (REILLY, 1997). Accordingly, their training program aims at developing several abilities, such as speed, muscular strength and cardiorespiratory endurance, along with technical and tactical competences. The combination of multiple training sessions per week with one or two competitive matches over the season complicates the balance between training/competitive loads and recovery periods in order to induce positive physiological adaptations. To date, however, there is relatively few information available on the training/competitive loads of elite soccer players and their effects on individual markers of physiological state, especially using accurate methods to training load quantification (ALEXIOU; COUTTS, 2008; IMPELIZZERI et al., 2004) and overreaching process evaluation (HEDELIN et al., 2000).

PICHOT et al. $(2000 ; \underline{2002})$ have shown that intensive running and cycling training periods induce sympathetic hyperactivity and reduced vagal outflow, which are implicated with impaired physical performance. Vagal modulation tends to recover and even rebound above baseline levels with tapering (PICHOT et al., 2000, 2002). The cardiac autonomic modulation at rest can be assessed by means of non-invasive recording of $R R$ intervals oscillations (i.e., heart rate variability HRV) using time and frequency domain algorithms 
(TASK FORCE, 1996).It was recently shown that individualized training based on resting HRV (i.e. decreased training stimulus when resting HRV was decreased or maintenance of training when HRV was constant or increased) led to greater cardiorespiratory fitness improvement than standard predefined training program (KIVINIEMI et al., 2007). Therefore, maintenance or improvement of HRV indices over the training period is thought to be an important condition to optimize training adaptations. However, there are only few reports on HRV measures in response to soccer training (REBELO et al, 1997) which suggest the absence of autonomic changes after a detraining period following a 6-week training period. Hence, the usefulness of HRV to monitor individual changes to soccer training periods remains to be elucidated.

The aim of this study was to monitor changes in HRV indices of two players of the same soccer team during a training period while performing similar training loads and attending the same matches. Our hypothesis was that despite similarity in the training/competitive loads, different patterns of individual autonomic responses would be detected.

\section{Methods}

Two male players of the same team competing in the First Division of a State Championship in Brazil (2007) were monitored over 3 weeks in regards to training/competitive loads and resting HRV on selected days. We intended to induce similar external and internal training loads to investigate their individual HRV responses. The physical trainer reported that athlete 1 had better readiness and physical performance than athlete 2 over the observation period, whilst athlete 2 reported sleep disturbances, subjective fatigue during the training sessions and disturbed recovery between sessions, which culminated with his substitution as a starter in the matches at the end of observation period. We consider the present case study suitable to show the usefulness of HRV to monitor the autonomic state as a method of training load control for soccer players due to the ecological validity of the training scheme adopted.

\section{Subjects}

The characteristics of the mid-fielder and right back players are shown in table 1 . The maximal oxygen consumption estimate was derived from a field test (LEGER; LAMBERT, 1982). They were in the competitive period at the time of observation, whose procedures had approval of the local Ethics Committee (no 399/2007) as a part of a major project. They signed an informed consent form before data collection.

Table 1. Athletes' characteristics.

\begin{tabular}{|c|c|c|c|c|c|}
\hline & $\begin{array}{c}\text { Age } \\
\text { (years) }\end{array}$ & $\begin{array}{l}\text { Years as } \\
\text { professional }\end{array}$ & Position & $\%$ body fat & $\begin{array}{c}V_{2 m a x} \\
\text { mL.(Kg-min) }\end{array}$ \\
\hline Athlete 1 & 26 & 7 & Mid-fielder & 10,1 & 60,8 \\
\hline Athlete 2 & 19 & 1 & right back & 10,6 & 62,3 \\
\hline
\end{tabular}

\section{Experimental protocol}

Training loads of each session of the 3-week period were monitored by means of the training impulses (TRIMP) method as proposed by $\underline{\text { Stagno }}$ et al. (2007) for team sports players. Briefly, heart rate (HR) values (Polar RS800) recorded at each 5-s intervals throughout a training session were used to determine the accumulated time spent at five training zones, then weighted and summed to result in an arbitrary units (a.u.) TRIMP value. Training sessions consisted mainly of small-sided games, simulated matches, strength sessions, sprint training and low-intensity aerobic training during recovery. The sessions were conducted once or twice a day 5 times a week, including a game on the sixth day and one day off. Both players were starters in 3 matches over the observation period (friendly match on Friday of the first week and 2 championship matches on Saturday of the second and third weeks).

Resting RR intervals were obtained at five moments: M1 (Saturday), M2 (Monday), M3 (Saturday), M4 (Monday) and M5 (Saturday). The data recorded on Saturdays aimed to detect the influence of accumulated weekly training load on HRV indices, while Monday recordings quantified the effects of 48 (M2) and $36 \mathrm{~h}$ (M4) of post-match recovery.

To record the RR intervals (Polar RS800), the subjects laid supine for 15 -min (8-10 a.m.) in a quiet room. The last 5 -min period was retained for analysis. Editing of artifacts was performed using default automated protocols within Polar Precision Performance software program, with moderate filter power, as suggested by Nunan et al. (2008). Subjects were allowed to breathe spontaneously, but without talking, since normal respiratory rate does not result in significantly different HR-derived 
indices compared with controlled breathing (BLOOMFIELD et al., 2008).

The time domain analysis provides statistical indices that reflect the absolute variation of consecutive RR intervals, which are thought to reflect the cardiac parasympathetic modulation. The standard deviation of normal RR intervals (SDNN), percentage of normal RR intervals greater than $50 \mathrm{~ms}$ (pNN50) and root-mean-
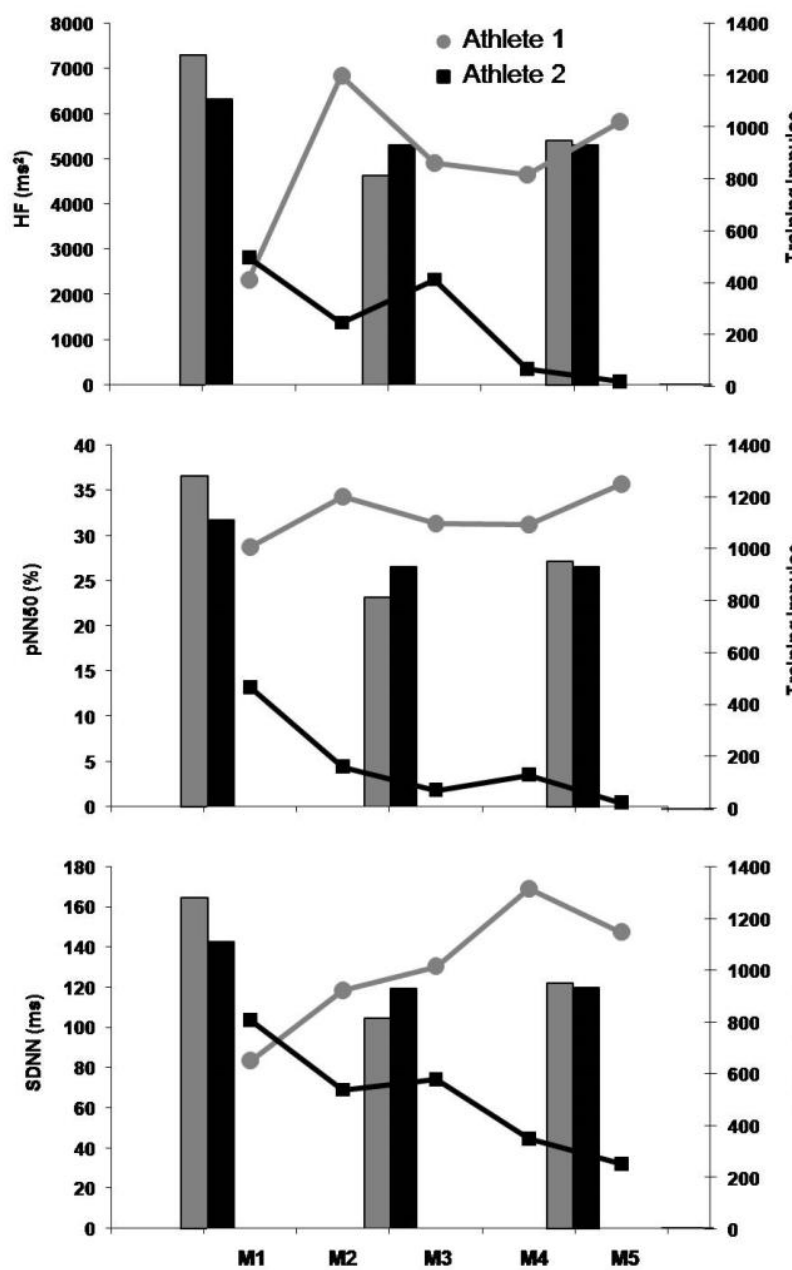

square difference of successive normal RR intervals (RMSSD) were retained. The frequency domain analysis was performed using an autoregressive method, resulting in a vagalrelated index: power density in the high frequency band $(\mathrm{HF},>0.15-0.40 \mathrm{~Hz}$ ). Finally, the Poincaré scatterplot was used to obtain the standard deviation of instantaneous beat-to-beat variability data, in which each RR interval is plotted as a function of the previous one (figure 2).

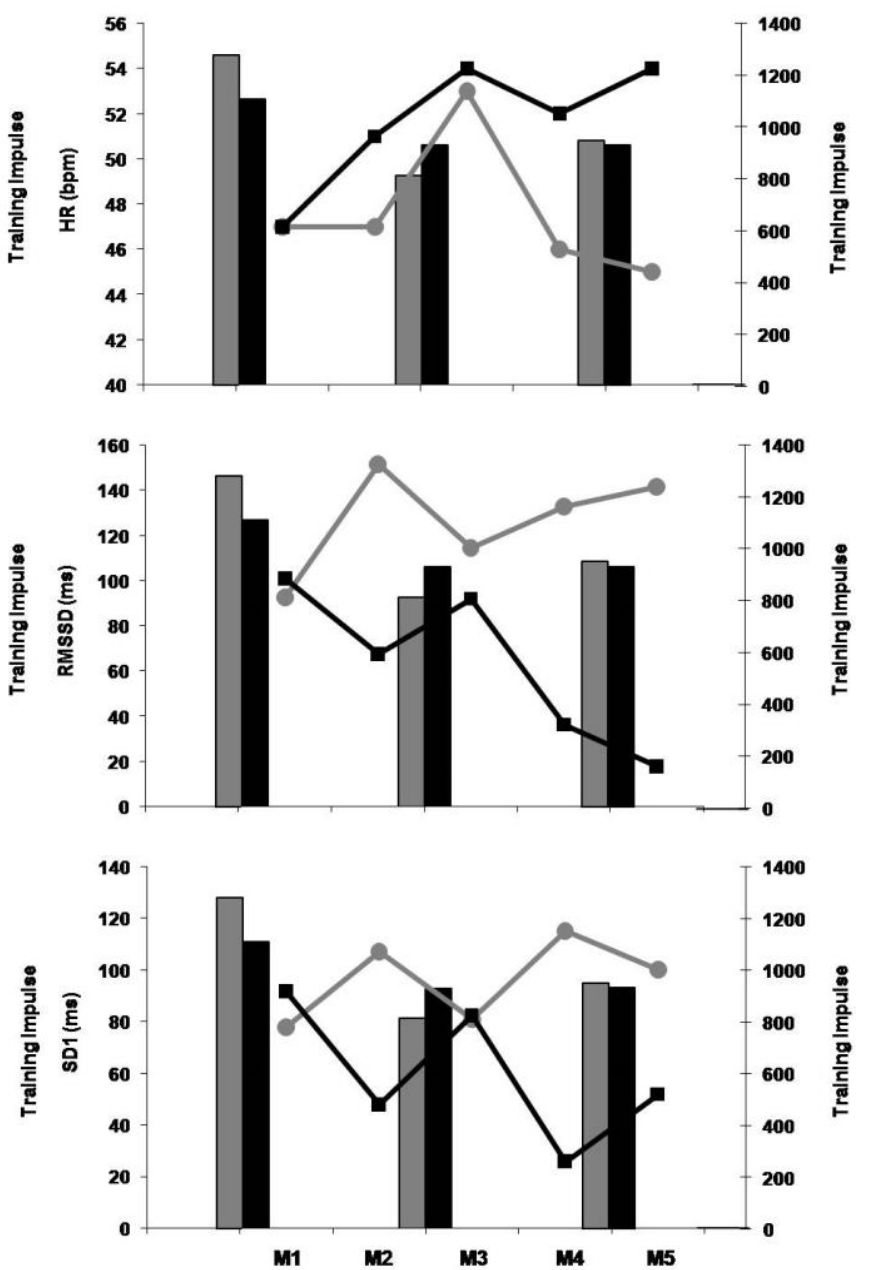

Figure 1. Resting HR, SD1, SDNN, pNN50, RMSSD and HF of the two soccer players at the five moments of the observation period and individual weekly TRIMP.

The HRV indices of the two players were compared at each moment to verify possible differences in the autonomic adaptations to the training/competitive loads imposed.

The athletes displayed similar TRIMP during the three monitored weeks which are depicted with HRV values (Figure 1). Total weekly TRIMP amounted were 1280, 814, 930 a.u. for athlete 1 and 110, 930, 932 for athlete 2 , respectively.

The resting parasympathetic modulation indices over the 5 moments (M1-M5) are displayed in figure 1. At M1, the resting $\mathrm{HR}$ was identical. From this moment on, HR of athlete 2 was invariably higher than of athlete 1 . The HRV indices (SD1, SDNN, RMSSD and HF) followed a similar pattern when comparing the two athletes. They had similar values at M1 and, from M2 on, these variables were greater in athlete 1 than in athlete 2. At M2 and M4, athlete 1 presented a parasympathetic rebound, especially in SD1, SDNN and RMSSD, whereas athlete 2 presented with a reduction of these indices. 
Only pNN50 remained higher in athlete 1 in relation to athlete 2 throughout the observation period, including M1. It is important to note that pNN50 of athlete 2 decayed along with M1-M5 progression.
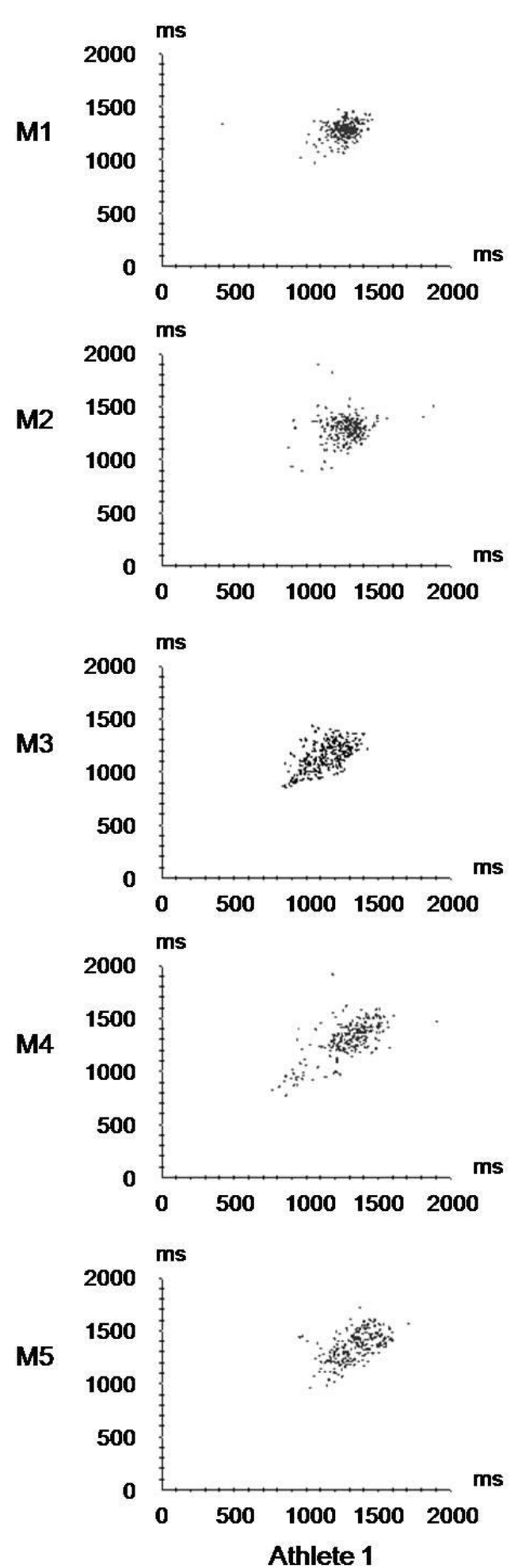

The Poincaré plots at each moment are displayed in figure 2. The dispersion of the scatterplot was similar at M1. However, from M2 to M5 athlete 1 had increases in the scattering of points, while athlete 2 presented the opposite pattern.
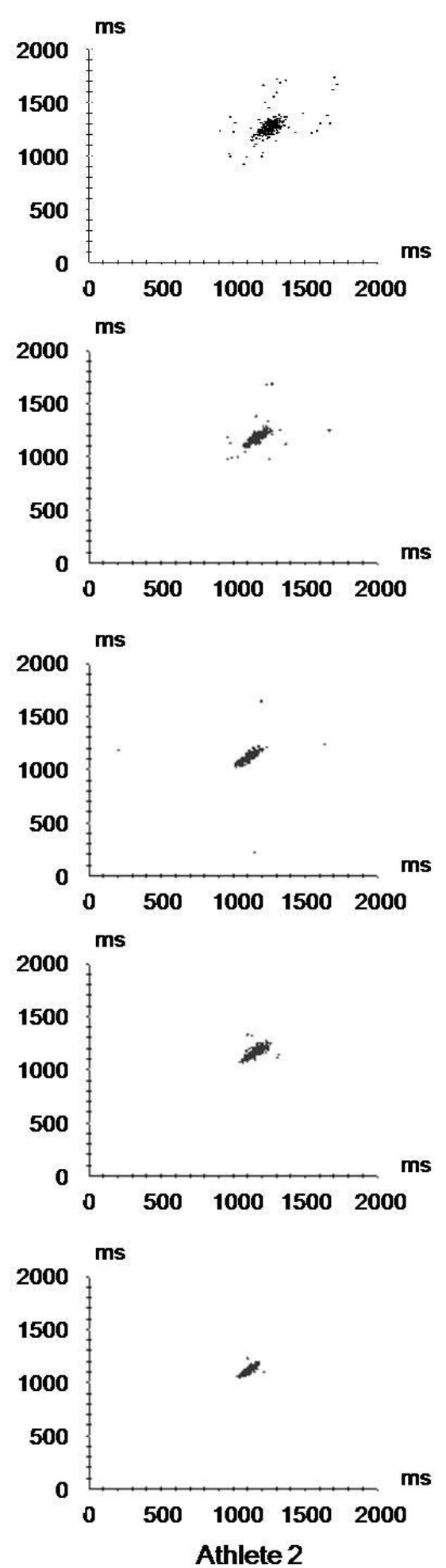

Figure 2. Resting Poincaré plot in the supine position of the two soccer players at the five moments of the observation period. 


\section{Discussion}

Since Bosquet et al. (2008) have recently concluded that modifications of resting $\mathrm{HR}$ in response to fatiguing training periods may be biased by the fact that differences may fall within the day-to-day amplitude of variation, we have opted to investigate the usefulness of selected HRV indices. Confirming our hypothesis, the two soccer players exhibited individual resting HRV patterns that differed markedly over 3 weeks, despite similar initial values and comparable physical stress imposed by training and competitive matches.

The SD1, SDNN, pNN50, RMSSD and HF component, as well as the Poincaré plot, reflect the short-term oscillation of the RR signal, being mainly determined by the parasympathetic control of the sinus node (TASK FORCE, 1996). They are generally highly correlated (PENTTILA et al., 2001). This possibly explains why the withinsubject patterns of variation in HRV were relatively consistent. Athlete 2 exhibited a reduction in HRV indices over the period of observation, whereas athlete 1 increased the vagally-mediated indices. At M2 and M4 (recovery periods), athlete 1 presented with marked increases in SDNN, RMSSD and SD1 (figure 1), suggesting a sufficient recovery period between microcycles. This trend could also be observed in the scattering of RR intervals in the Poincaré plots (figure 2). In contrast, athlete 2 exhibited a progressive impairment of vagal modulation, indicating insufficient recovery and/or other prevalence of stressors unrelated to sport (e.g., emotional disruptions). Unfortunately, we could not confirm this hypothesis objectively because no questionnaires of mood state or recovery-stress were used. Nevertheless, the physical trainer reported complaints of athlete 2 regarding sleep disturbances, subjective fatigue in training and disturbed recovery between sessions. These symptoms, associated with poor autonomic indices, may indicate a state of non-functional overreaching (PLEWS et al., 2012). However, it should be noted that a multitude of biochemical, physiological and psychological variables could be additionally measured to support this assumption (HALSON; JEUKENDRUP, 2004).

The HF component followed the pattern of the other HRV measures, since both athletes commenced the observation period with comparable values but, after $M 1$, athlete 1 invariably presented greater vagal modulation. The exception was M4, at which athlete 1 did not experience a rebound in the HF component. It may suggest less sensitivity of this index in comparison to SDNN, RMSSD and SD1. Possibly, measuring the RR intervals in the standing position would induce orthostatic challenge to the autonomic regulation by shifting the balance to greater sympathetic activity (KIVINIEMI et al., 2007), and then highlight the parasympathetic rebound. The comparison between body postures (i.e., supine versus upright) on HRV responses to soccer training should be tested in future in order to establish the proper measurement position. It should be noted that measuring RR intervals in the supine position may increase the likelihood of saturation of vagal-related indices (e.g., HF). This phenomenon is regarded to unchanged HF in spite of increasing RR intervals (i.e., bradycardia), evidencing a lack of sensitivity of HRV measures in response to increased vagal modulation (KIVINIEMI et al, 2006). Hence, our body position choice may have partially biased our results.

The pNN50 was the only index that differed between athletes in $\mathrm{M} 1$, and this difference persisted in the following moments. This may indicate its predictive ability at the early phases of overreaching. Alternatively, since it has not varied in magnitude in comparison to the other HRV indices throughout the observation period, one may assume that pNN50 has low sensitivity to the oscillations in the autonomic function, even clearly showing differences between athlete 1 and 2. This index deserves future investigations to be reliably included in monitoring routines of soccer players.

The lack of positive autonomic adaptations in athlete 2 may be related to a lower level of playing experience as a professional (table 1). He also reported that this was his second season without any vacation period. Alternatively, it may reflect an individual characteristic of responsiveness to training loads, which should be taken into account while scheduling training intensities and duration (HALSON; JEUKENDRUP, 2004).

Individual responses to similar internal and external as shown between both studied athletes may explain different HRV kinetics. The same load must not always represent similar responses from different athletes, eliciting distinct adaptations on them. This must be an important point to be control in the sports training and physical activities contexts. 
Another factor that must be point out is the presence of three matches (two official matches) during the observation period. It may also have influenced the differences in HRV responses since psychological factors may induce HRV alterations (MATEO et al., 2012).. The younger player may have been more prone to be influenced by emotional challenges since it was his first professional championship.

From the results of this study, we can indicate that SDNN, RMSSD and SD1 indices of heart rate variability can be useful to monitor the effects of soccer training/competitive loads on parasympathetic modulation, being sensitive to both individual characteristics and to periods of stress and recovery. The maintenance and/or increase in heart rate variability seems to be a desirable condition to keep the soccer player able to tolerate training and matches and exhibit optimal performance throughout the season. Therefore, we suggest the monitoring of resting HRV indices to make daily adjustments of the planned loads in order to avoid overreaching symptoms.

\section{References}

ALEXIOU, H.; COUTTS, A.J. A comparison of methods used for quantifying internal training load in women soccer players. International Journal of Sports Physiology and Performance, v.3, n.3, p.320-330, 2008. Disponível em:

http://hk.humankinetics.com/IJSPP/viewarticle.cf m?jid=XhUcQX8xXxDrGE8EXvBtBJHQXpDpZJA 8XgNmYD\&aid $=16197 \&$ site $=$ XhUcQX8xXxDrGE8 EXvBtBJHQXpDpZJA8XgNmYD. Acesso em 10 de Janeiro de 2011

BLOOMFIELD, D.M.; MAGNANO, A.; BIGGER, J.T.; RIVADENEIRA, H.; PARIDES, M.; STEINMAN, R.C. Comparison of spontaneous vs. metronome-guided breathing on assessment of vagal modulation using $R R$ variability. American Journal of Physiology. Heart Circulation Physiology, Bethesda, v.280, n. 3, p. H11451150, 2001. Disponível em:http://ajpheart.physiology.org/content/280/3/H1 145.full.pdf. Acesso em 26 de março de 2011.

BOSQUET, L.; MERKARI, S.; ARVISAIS, D.; AUBERT, A.E. Is heart rate a convenient tool to monitor over-reaching? A systematic review of the literature. British Journal of Sports Medicine, Loughborough. v.42, n. 9, p. 709-714, 2008. DOI: http://dx.doi.org/10.1136/bjsm.2007.042200
HALSON, S.L.; JEUKENDRUP, A.E. Does overtraining exist? An analysis of overreaching and overtraining research. Sports Medicine, Auckland v.34, n. 14, p. 967-981, 2004.

HEDELIN, R.; KENTTÁ, G.; KIKLUND, U.; BJERLE, P.; HENRIKSSON-LARSÉN, K. Shortterm overtraining: effects on performance, circulatory responses, and heart rate variability. Medicine and Science in Sports and Exercise, Hagerstown , v.32, n. 8, p. 1480-1484, 2000.

IMPELLIZZERI, F.M.; RAMPININI, E.; COUTTS, A.J.; SASSI, A.; MARCORA, S.M. Use of RPEbased training load in soccer. Medicine and Science in Sports and Exercise. Hagerstown. v.36, n. 6, p.1042-1047, 2004.

KIVINIEMI, A.M.; HAUTALA, A.J.; MÄKIKALLIO, T.H.; SEPPÄNEN, T.; HUIKURI, H.V.; TULPPO, M.P. Cardiac vagal outflow after aerobic training by analysis of high-frequency oscillation of the R-R interval. European Journal of Applied

Physiology. Berlin. v. 96, n. 6, p.686-692, 2006.

KIVINIEMI, A.M; HAUTALA, A.J.; KINNUNEN, H.; TULPPO, M.P. Endurance training guided individually by daily heart rate variability measurements. European Journal of Applied Physiology. Berlin. v.101, n. 6, p.743-751 2007. DOI: http://dx.doi.org/10.1007/s00421-007-0552-2

LEGER, L.A.; LAMBERT, J. A maximal multistage $20 \mathrm{~m}$ shuttle run test to predict $\mathrm{VO}_{2 \max }$, European Journal of Applied Physiology. Berlin, v. 49, p.1-5, 1982.

MATEO, M.; BLASCO-LAFARGA, C.; MARTÍNEZ-NAVARRO, I.; GUZMÁN, J.F.; ZABALA, M. Heart rate variability and precompetitive anxiety in BMX discipline. European Journal of Applied Physiology. Berlin. v. 112, n. 1, p. 113-123, 2012.

NUNAN, D.; JAKOVLJEVIC, D.G.; DONOVAN, G.; HODGES, L.D.; SANDERCOCK, G.R.; BRODIE, D.A. Levels of agreement for RR intervals and short-term heart rate variability obtained from the Polar S810 and an alternative system. European Journal of Applied

Physiology. Berlin. v.103, n. 5, p. 529-537, 2008. DOI: http://dx.doi.org/10.1007/s00421-008-0742-6

PENTTILÄ, J.; HELMINEN, A.; JARTTI, T.; KUUSELA, T.; HUIKURI, H.V.; TULPPO, M.P.; COFFENG, R.; SCHEININ, H. Time domain, geometrical and frequency domain analysis of cardiac vagal outflow: effects of various respiratory patterns. Clinical Physiology. Oxford. v.21, n. 3, p. 365-376, 2001.

PICHOT, V.; BUSSO, T.; ROCHE, F.; GARET, M.; COSTES, F.; DUVERNEY, D.; LACOUR, J.R.; 
BARTHÉLÉMY, J.C. Autonomic adaptations to intensive and overload training periods: a laboratory study. Medicine and Science in Sports and Exercise. Hagerstown. v.34, n. 10, p. 1660-1666, 2002.

PICHOT, V.; ROCHE, F.; GASPOZ, J.M.; ENJOLRAS, F.; ANTONIADIS, A.; MININI, P.; COSTES, F.; BUSSO, T.; LACOUR, J.R.; BARTHÉLÉMY, J.C. Relation between heart rate variability and training load in middle-distance runners. Medicine and Science in Sports and Exercise. Hagerstown. v.32, n. 10, p.1729-1736, 2000. Disponível em:http://courses.ttu.edu/jrobert/Weblist\%20HRV \%20articles/hr\%20variability\%20distance\%20runni ng.pdf. Acesso em 26 de março de 2013.

PLEWS, D.J.; LAURSEN, P.B.; KILDING, A.E.; BUCHHEIT, M. Heart rate variability in elite triathletes, is variation in variability the key to effective training? A case comparison.. European Journal of Applied Physiology. Berlin, v.112, n. 11, p. 3729-3741, 2012. DOI: 10.1007/s00421012-2354-4 REBELO, A.N.; COSTA, O.; ROCHA, A.P.; SOARES, J.M.; LAGO, P. Is autonomic control of the heart rate at rest altered by detraining? A study of heart rate variability in professional soccer players after the pretraining period and after preparatory period for competitions. Revista Portuguesa de Cardiologia. Lisboa, v.16, n. 6, p. 535-541, 1997.

REILLY, T. Energetics of high-intensity exercise (soccer) with particular reference to fatigue.

Journal of Sports Sciences. London, v.15, n. 3, p.257-263, 1997.

STAGNO, K.M.; THATCHER, R.; SOMEREN, K.A. A modified TRIMP to quantify the in-season training load of team sports players. Journal of Sports Sciences. London, v.25, n. 6, p. 629-634, 2007.

TASK FORCE OF THE EUROPEAN SOCIETY OF CARDIOLOGY AND THE NORTH AMERICAN SOCIETY OF PACING AND ELECTROPHYSIOLOGY. Heart rate variability: standards of measurement, physiological interpretation and clinical use. Circulation. Hagerstown. v.93, n. 5, p. 1043-1065, 1996. Disponível em: http://circ. ahajournals.org/cgi/content/full/93/5/104 $\underline{3}$. Acesso em 26 de março de 2013.
Corresponding author:

Maurício Bara-Filho

Rua Santo Antônio - 1005/1002

Juiz de Fora MG Brazil

36016-210

e-mail: mgbara@terra.com.br

Recebido em: 27 de março de 2011.

Aceito em: 19 de fevereiro de 2013.

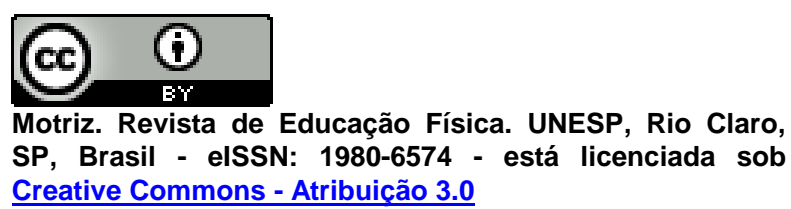

